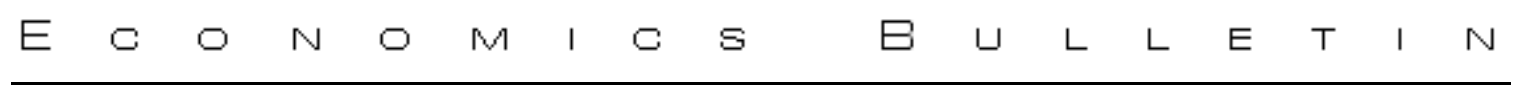

\title{
Does the US IT stock market dominate other IT stock markets: Evidence from multivariate GARCH model
}

\author{
Zhuo Qiao \\ Department of Economics, National University of Singapore
}

Venus Khim-Sen Liew

Labuan School of International Business and Finance, Universiti Malaysia Sabah

\author{
Wing-Keung Wong \\ Department of Economics, National University of \\ Singapore
}

\begin{abstract}
Utilizing multivariate GARCH framework, this study finds that generally the US Information Technology (IT) market contributes a strong volatility rather than mean spillover effect to non-US IT markets, implying that the US IT market plays a dominant role in affecting the volatility of world IT markets. However, our further analysis of the dynamic path of correlation coefficients reveals that the strong relationship between US and non-US IT markets had weakened after the burst of the IT bubble.
\end{abstract}

\footnotetext{
Citation: Qiao, Zhuo, Venus Khim-Sen Liew, and Wing-Keung Wong, (2007) "Does the US IT stock market dominate other IT stock markets: Evidence from multivariate GARCH model." Economics Bulletin, Vol. 6, No. 27 pp. 1-7

Submitted: November 11, 2006. Accepted: August 2, 2007.

URL: http://economicsbulletin.vanderbilt.edu/2007/volume6/EB-06F30029A.pdf
} 